ORIGINAL STUDY

\title{
Epistaxis management - our point of view and literature review
}

\section{Violeta Melinte ${ }^{1,2,3}$, Oana Musteata ${ }^{2,3}$, Codrut Sarafoleanu $u^{1,2,3}$}

${ }^{1}$ Centre of excellence for research of sensorial and sensitive disorders, study of inceto-inflammatory, tumoral and obstructive aero-digestive pathology (CESITO), ENT\&HNS Department, "Sfanta Maria" Clinical Hospital, Bucharest, Romania

${ }^{2}$ ENT\&HNS Department, "Sfanta Maria” Clinical Hospital, Bucharest, Romania

"Carol Davila” University of Medicine and Pharmacy, Bucharest, Romania

\section{ABSTRACT}

Nasal haemorrhage or epistaxis is the most common otolaryngologic emergency. It affects about $60 \%$ of the population and a percentage of $6 \%$ do not cease spontaneously, medical approach being needed.

The management of epistaxis varies depending on its severity and etiology. The therapeutic conduct of this ENT emergency is based on three main principles: 1. local haemostasis; 2. detection and ceasing of the cause; 3 . evaluation and correction of hypovolemia if necessary. Haemostasis can be done by chemical or electric cauterisation after identifying the bleeding source, by nasal packing, by endoscopic or external surgery or, in special cases, when none of the above methods returns any results, embolization. The current paper emphasizes our experience and a brief literature concerning epistaxis management in patients presented in the Emergency Room, in chronic cases of vascular intranasal tumors with recurrent bleeding, in iatrogenic haemorrhages, and none of the least we will bring into discussion the treatment applied for patients diagnosed with hereditary hemorrhagic telangiectasia.

KEYWORDS: epistaxis, haemostasis, electric cauterisation, hereditary hemorrhagic telangiectasia.

\section{INTRODUCTION}

Epistaxis is a common ENT emergency, as $60 \%$ of the population have at least one nasal bleeding episode in their lives and about $6 \%$ of them need medical assistance ${ }^{1}$. Epistaxis is the second most common cause of spontaneous bleedings. The bleeding episode can be minor and ceases spontaneously or so severe as to be fatal ${ }^{2}$. It can be encountered as an emergency, as a chronic disease of recurrent bleeding or as a symptom in a systemic illness ${ }^{3}$.

Commonly, epistaxis occurs from the anterior part of the nasal cavity, usually from the Kiesselbach's plexus or from the retrocolumellar vein. Eighty per cent of epistaxis occurs in Kiesselbach's plexus ${ }^{4}$. The Kiesselbach plexus (also known as Little's area) is located on the lower third of the septal cartilage and $90 \%$ of anterior nosebleeds ${ }^{5}$ are located in this area. Many of the arteries supplying the septum have anastomotic connections in this plexus.
The various sites of bleeding in case of posterior epistaxis include Woodruff's plexus situated on the posterior aspect of the lateral wall of the inferior meatus, the posterior part of the lateral nasal wall near the sphenopalatine foramen, the posterior end of the inferior turbinate, the middle turbinate and its medial surface, the middle and posterior parts of the nasal septum and the floor of the nose beneath the inferior turbinate ${ }^{6}$. In case of posterior epistaxis, the bleeding source might not be visualized on anterior rhinoscopy because of its posterior location, an endoscopic examination of the nasal fossa being more accurate in this situation ${ }^{7}$.

It is well known that the nasal blood supply is a contribution from both internal and external carotid arteries. The external carotid system delivers blood via the facial and the internal maxillary arteries. The superior labial artery is one of the terminal branches of the facial artery and contributes to the blood supply of the anterior part of the nasal floor and of the septum. The internal maxillary artery enters the pterygomaxil- 
lary fossa and divides into 6 branches: superior alveolar, descending palatine, infraorbital, sphenopalatine, pterygoid canal and pharyngeal ${ }^{8}$.

The sphenopalatine artery is the most probable source for posterior bleeds. The internal carotid artery irrigates the nose through the ophthalmic artery that enters the bony orbit via the superior orbital fissure and divides into several branches (anterior and posterior ethmoidal arteries) ${ }^{8}$.

There are multiple causes of epistaxis which can be divided into local and systemic ${ }^{4}$.

Local causes include nasal trauma (fractures, selfinduced digital trauma, foreign body), allergic, chronic or infectious rhinitis, chemical irritants (cocaine abuse, ammonia, gasoline, phosphorus, chromium salts, sulphuric acid), medications (nasal sprays-steroids and decongestants), dryness of the nasal mucosa, intranasal tumors - benign (e.g. nasopharyngeal angiofibroma, inverted papilloma, polyp of the nasal septum (Figure 1), etc.) and malignant (e.g. carcinoma, malignant melanoma or lymphoma), anatomical anomalies such as nasal septum deviation (Figure 2) or perforation, postoperative bleeding ${ }^{9}$.

Systemic causes ${ }^{10}$ may include cardiovascular diseases (e.g. systemic arterial hypertension, atheromatosis and atherosclerosis), hematologic diseases (e.g. von Willebrand disease, hereditary hemorrhagic telangiectasia, vascular malformations ${ }^{11}$ or haemophilia, parahaemophilia ${ }^{12}$ ), hepatic disease ${ }^{13}$ (cirrhosis and hepatic failure), endocrine causes (pregnancy, puberty or pheochromocytoma) and systemic medication (anticoagulants or NSAIDs).

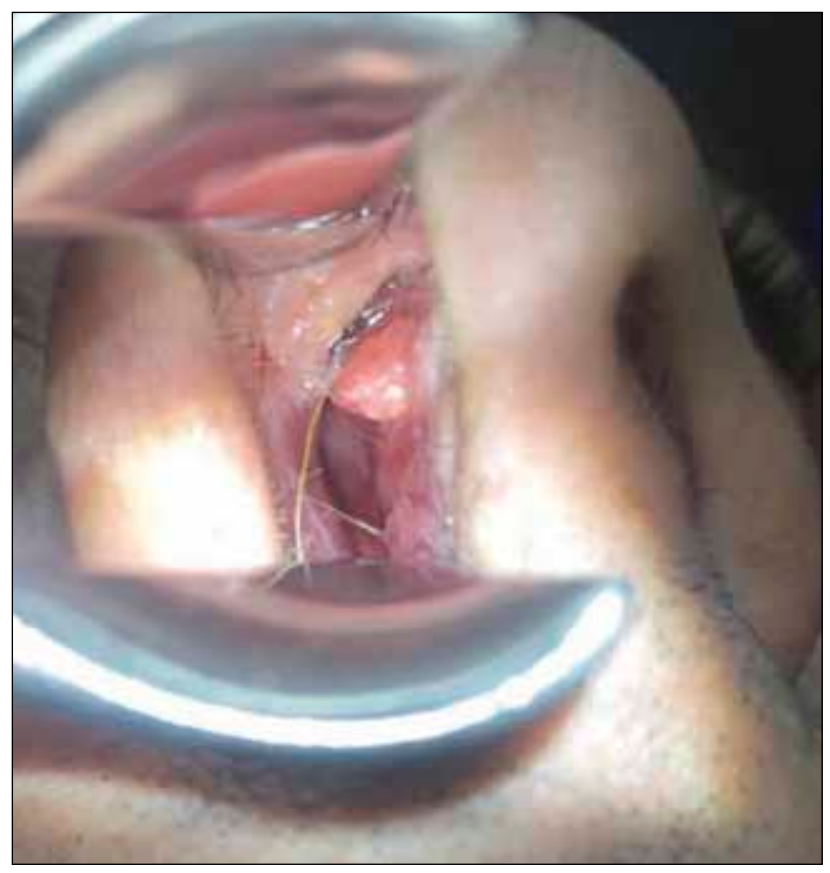

Figure 1 Nasal septum polyp (archive of ENT\&HNS Department, "Sfanta Maria" Clinical Hospital).
No matter the type or the severity of the epistaxis, the correct management is essential.

\section{HOW TO MANAGE A PATIENT WITH EPI- STAXIS?}

In front of a patient presenting a medium or severe nasal bleed, there are three fundamental steps that an ENT specialist should follow: general management, local management and a rigorous anamnesis.

The general management is based on position control (bent forward in order to avoid blood swallowing with subsequent nausea and vomiting), becalming the patient and his family and bleeding quantity estimation $^{14}$. The bleeding quantity is estimated using clinical examination (pallor, tachycardia, pulse, arterial tension, polypnea) and paraclinical signs (complete blood count, coagulation tests); in case of massive bleeding, fluid resuscitation is applied through a vein catheter. At the same time, a detailed history of the patient must be obtained in order to discover existing comorbidities (cardiologic illness, known intranasal tumors, hepatic diseases, haematological diseases, etc.) or chronic treatment that can influence the clotting time (anticoagulant medication, NSAIDs).

In what concerns the local management, the nasal fossae must be discharged of any blood clots (bleeding risk) and local cottons soaked in anaesthetic and vasoconstrictor are held in place up to 10 minutes $^{9}$. At this point, an endoscopic examination is mandatory because it offers a systematic and rigorous examination of the nasal cavity with the highlighting of the bleeding source and immediate local treatment (electrocauterization) can be applied. This type of assessment avoids the undesired situations of establishing a wrong diagnosis caused by an incomplete examination and the omission of the real bleeding source, because the doctors must be aware of the fact that, even though

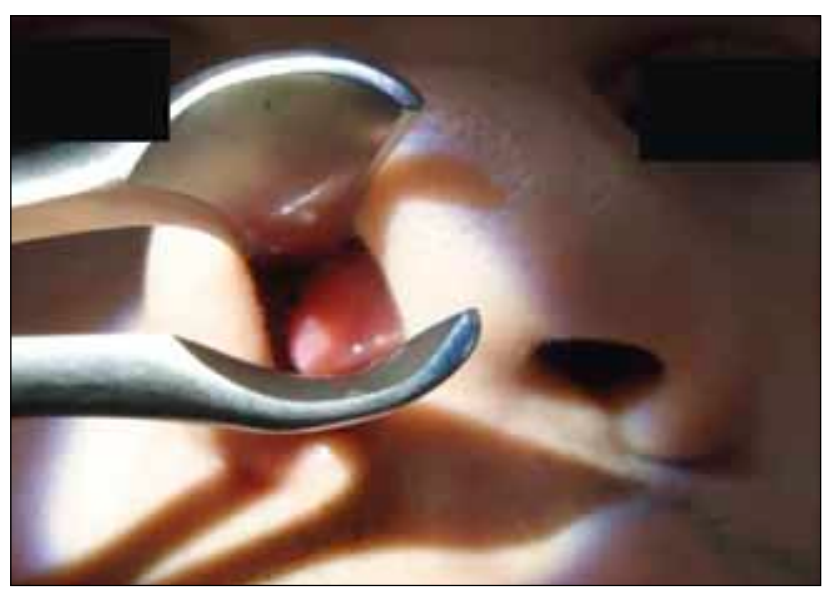

Figure 2 Nasal septum deviation (archive of ENT\&HNS Department, "Sfanta Maria" Clinical Hospital). 
systemic hypertension is the most common cause of epistaxis ${ }^{15}$, it is not the only one.

Regarding the epistaxis treatment ${ }^{16}$, there are three treatment alternatives: primary, secondary and tertiary intention methods, depending on the bleeding severity.

\section{Primary intention treatment methods}

Primary intention methods are local digital compression, local vasoconstrictor - efficient in case of a slight nose bleeding, chemical cauterisation and anterior nasal packing. Chemical cauterisation is a valuable method for a slight nosebleed with anterior localization which is easily identifiable ${ }^{17}$. The most commonly used chemical agent is silver nitrate, but there are also reported cases of chemical cauterization with trichloroacetic acid or chromic acid ${ }^{18}$.

Newton et al., in a retrospective study published in April 2016, analysed the effectiveness of different anterior epistaxis treatment methods performed in the Emergency Department (silver nitrate cauterization, petroleum gauze packing, Merocel®, nasal clip or simple observation $)^{19}$. They concluded that cauterization with silver nitrate returned best results in terms of recurrence and follow-up, compared to the Merocel® packing and petroleum gauze packing outcomes.

Recently, Johnson et al. made a comparison between the bipolar electrocautery and chemical cautery in recurrent anterior epistaxis in children ${ }^{20}$. They pointed out that within 2 years of treatment the bleeding recurrence was lower and the nosebleed-free period was longer in electrocauterized patients than those treated using the silver nitrate cauterization.

The most frequent complications that can occur after chemical cauterization are represented by nasal septum perforation (especially when performed on both sides at the same time), local scars, intranasal mucosal adhesions, even necrosis ${ }^{21}$.

Concerning the anterior nasal packing, there are numerous options available, such as ribbon gauze (traditional nasal packing), Merocel ${ }^{\circledR}$ (polyvinyl acetate sponge), fingerstall packs, Rapid Rhino ${ }^{\circledR 2}{ }^{22}$, but nor are they free of risks and complications.

A prospective study of 42 patients with epistaxis was performed in order to compare two types of anterior nasal packing, Merocel ${ }^{\circledR}$ and Rapid Rhino ${ }^{\circledR}$. There was no significant difference found regarding their efficacy and patient discomfort during intranasal maintenance. Related to the insertion and removal of the pack, Rapid Rhino ${ }^{\circledR}$ registered lower scores for subjective patient pain ${ }^{23}$.

\section{Secondary intention treatment methods}

The secondary methods consist in the posterior nasal packing, which is applied when the primary methods failed or in case of a posterior epistaxis ${ }^{24}$. In most of the cases, the anterior nasal packing is also required for a complete haemostasis.

In 2010, Garcia Callejo et al. ${ }^{25}$ evaluated the tolerance (pain intensity during the placement and maintenance of the packing) and the efficacy (referring to recurrence, concomitant measures, side effects and need for blood transfusion) of two posterior nasal packing methods: bi-chamber pneumatic inflation system and posterior packing with gauze. The classic posterior packing with gauze resulted to be more effective, as it confers a lower recurrence rate of posterior nasal bleeding $(17 \%)$ even though it is more painful and difficult to perform, while the inflatable nasal packing placement was faster and less painful, but the rate of rebleeding was higher $(26 \%)$. A price difference was also registered, the classic packing being cheaper.

\section{Why NOT nasal packing?}

Apart from the high failure rate of $26-50 \%$ associated with antero-posterior nasal packing ${ }^{26}$, it creates a marked discomfort (hard to be tolerated by the patient, especially that it must be held for about 72-96 hours), pain and swallowing difficulty and it can lead to a large number of local and systemic complications like septal hematomas and abscesses, septal perforation, sinusitis, intranasal mucosal adhesions, otitis media, facial edema, tissue necrosis and perforation of the soft palate because of the local pressure, neurogenic syncope during the procedure, orbital complication or even toxic shock syndrome. In case of lack of packing fixation, there is also a risk of swallowing or aspiration. When posterior packing is secured, alar or columellar necrosis can occur ${ }^{27-29}$. A rare but severe complication of the posterior nasal packing using Foley catheter for posterior epistaxis associated with fracture of the skull base is the intracranial migration of the catheter ${ }^{30}$.

In view of these problems, patients with antero-posterior nasal packing need hospitalization, antibiotherapy and constant monitoring.

\section{Why YES endoscopic cauterization?}

Odat and Al-Qudah ${ }^{31}$ studied the use and results of monopolar cauterization under endoscopic control for posterior epistaxis originating from the sphenopalatine artery. They concluded that this technique offers a safe and effective management of the refractory nasal bleeding and they consider that it should be approached earlier in the treatment algorithm of intractable epistaxis.

Kaluskar $^{6}$ reported an efficacy of $90 \%$ of electrocauterization. In case of severe posterior epistaxis, cauterization in the operating room under general anaesthesia is recommended for safety and patient comfort and can be easily performed instead of nasal pack- 
ing $^{32}$. We have to admit that the doctor's experience with endoscopic surgery of the doctor has an important impact on the electrocauterization result.

Another recent paper published in 2015 by You Zou et al. ${ }^{33}$ also showed that endoscopic electrocauterization is more efficient compared to conventional nasal packing for the management of posterior epistaxis, because the rebleeding incidence, the patient discomfort and the incidence of intranasal synechiae were significantly lower in patients that underwent surgery than in those with nasal packing.

In the ENT departments that dispose of the necessary equipment, in order to avoid nasal packing, we also recommend the endoscopic cauterization, which was first described by Wurman et al. ${ }^{34}$. This can be easily done under local or general anaesthesia depending on the nosebleed severity and localization, has a good patient tolerance, has few side effects and the hospitalization is not mandatory, except for the situation of a patient with comorbidities that needs a careful follow-up.

\section{Tertiary intention treatment methods}

Last but not least, the tertiary methods are applied only when nasal bleeding exceeds 1,51 or the haemoglobin value is less than $8 \mathrm{~g} / 1$, when there are more than $72 \mathrm{~h}$ of uncontrolled haemorrhage, or when complications and contraindications of previous manoeuvres are encountered. These procedures include surgical haemostasis - external carotid artery ligation, internal maxillary artery ligation, sphenopalatine artery ligation, ethmoidal artery ligation and embolization ${ }^{16,35}$.

Small and Maran support early arterial ligation ${ }^{36}$. Arterial ligation has its own impediment. External carotid ligation can be easily performed under local anaesthesia, but there is a high risk of failure due to the anastomotic connections with the ipsilateral internal carotid or the opposite carotid system. Also, the ligation is performed far from the bleeding site and the drop in local blood pressure may not be substantial.
Ligation of the internal maxillary artery has been a popular method over the past several decades. Reported success rates range from 75 to $100 \%{ }^{37}$.

Complications include: persistent pain in the upper teeth; potential damage to the sphenopalatine ganglion and the vidian nerve, infraorbital neuralgia, oroantral fistula, sinusitis. The operation can be used on children, patients with maxillary sinusitis or hypoplastic antrum.

For patients with the bleeding source above the middle turbinate, ethmoidal artery ligation can be performed, but the indications are limited and the possibility of injuring the optic nerve and failure of the bleeding control do not make this method a choice ${ }^{38}$.

Percutaneous arterial embolization as an epistaxis treatment option was first described in 1974 by Sokoloff et al. ${ }^{39}$. This therapeutic alternative is not routinely used in emergency, being preserved for special situations like acute arterial bleeding, epistaxis that is unresponsive to the first and second intention haemostasis, vascular erosions in carcinomas or important bleeding after tonsillectomy. Percutaneous embolization is currently performed as a preoperative preparation in patients with intranasal tumors with a high bleeding potential (e.g. juvenile nasopharyngeal angiofibroma - Figure 3). Embolization is always preceded by angiography, in order to obtain the vascular lesions identification. Its principle is to make vascular obstruction by introducing different embolic agents (polyvinyl alcohol or Gelfoam are most used due to their safety and efficacy). According to the literature, the dimension range for the polyvinyl alcohol is between 150 and $350 \mu \mathrm{m}$ and for Gelfoam 1 to $3 \mathrm{~mm}^{40}$. The particles must be introduced near the bleeding source in order to avoid distal ischemic lesions. There are also complications of this radiointerventional procedure such as facial pain, lockjaw, facial edema, inguinal haematoma. Unfortunately, it is not infallible, because it cannot reach all the tumoral branches, par-

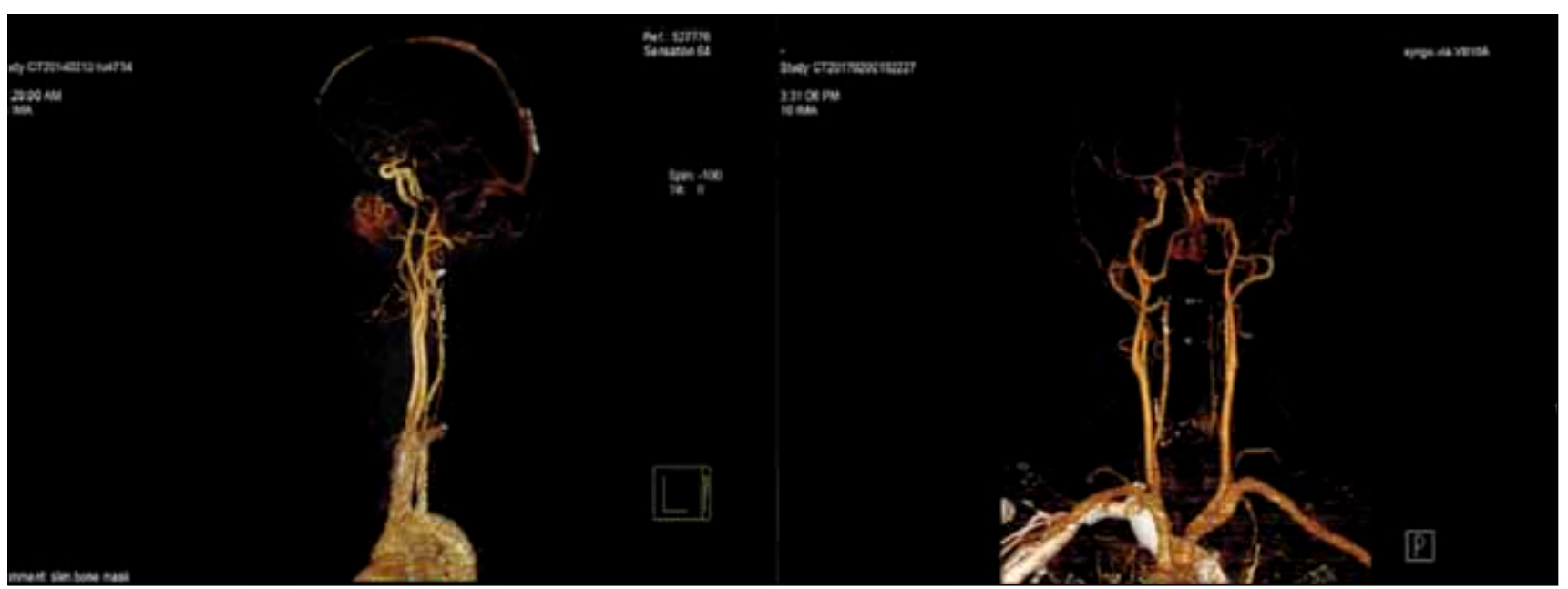

Figure 3 Juvenile nasopharyngeal angiofibroma - angiography (a- lateral and b-posterior view). 
ticularly the ones coming from the internal carotid artery (e.g. anatomical variant of the vidian artery as a branch of the internal carotid artery instead of the external carotid artery) and does not ensure us that an iatrogenic epistaxis could not be started during the tumor dissection ${ }^{41,42}$.

\section{“PARTICULAR" BLEEDING SITUATIONS}

Except emergency cases of epistaxis, there are also patients with "particular" bleeding situations: recurrent epistaxis in chronic systemic diseases (e.g. Hereditary Haemorrhagic Telangiectasia - HHT), "hidden" intranasal tumors, iatrogenic epistaxis or postoperative bleeding. The management of these patients must be adapted to each etiology to obtain best results.

An important rate of recurrence of nasal bleeding is present in the hematologic malformations like hereditary hemorrhagic telangiectasia, which is an uncommon autosomal dominant disease. The malformation affects the nose, skin, lungs, the gastrointestinal tract, the liver and the brain by the presence of telangiectasias - small dilated blood vessels with a thin wall (Figure 4).

Epistaxis is the most common symptom of HHT with nasal location, because the vessels are thin and fragile and the air flux produces dryness and rupture; this is an important factor that can decrease HHT patients' quality of life of the ${ }^{43}$.

The therapeutic options for the treatment of epistaxis in patients with HHT are many, but none of them dem- onstrated to be perfect. Starting with topical treatment that includes humidifiers, vaseline and estrogen - contending ointments, nasal packing, medical solutions (anti-estrogen therapy, iron supplements, immunosuppressors or anti-angiogenic drugs), local sclera-therapy, selective or supra-selective embolization, chemical cauterization or surgical solution using the electric cauterization and laser cauterization, none of these methods is the absolute solution of nasal bleeding ${ }^{4446}$.

In what concerns the "hidden" tumors, we will present further a short case description of a woman who came to our ENT department for recurrent nose bleeds. From her history, we found out that she suffered multiple nasal packing in different ENT departments (without identification of the underlying cause of epistaxis). No endoscopic evaluation was performed in the ENT departments she visited. We discovered a reddish, easily bleeding tumor of the left middle turbinate, in contact with the nasal septum, which was obstructing entirely the left osteomeatal complex (Figures 5, 6, 7).

Surgical treatment (tumor excision under endoscopic control) was performed after rigorous evaluation (endoscopic evaluation, cranio-facial CT scan, angiography) in the ENT Department of "Sfanta Maria" Clinical Hospital, and the anatomopathological result was recurrent cavernous haemangioma.

We want to point out here the major importance of the careful endoscopic examination, which unfortunately is not routinely used for diagnosis (even though it must) because of various reasons: lack of necessary equipment, the doctor does not have enough experi-
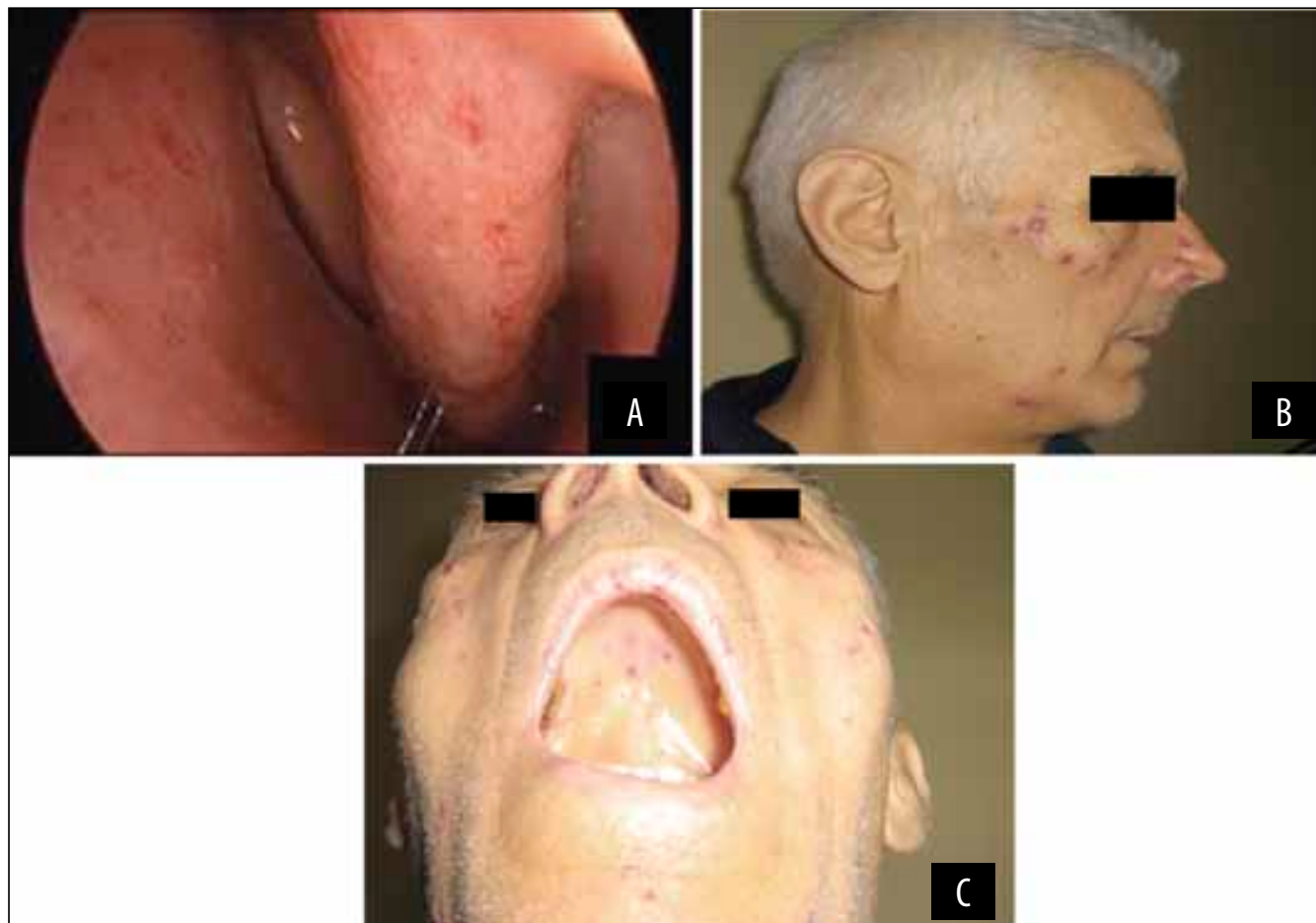

Figure 4 Rendu Osler patient: A. endonasal telangiectasias; B. skin lesions; C. oral mucosal telangiectasias. 


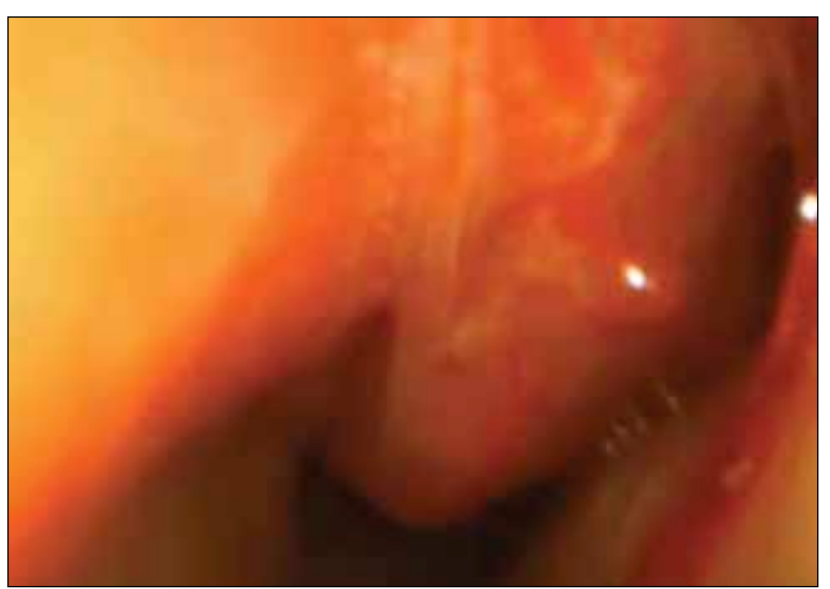

Figure 5 Endoscopic aspect - reddish, easily bleeding tumor of the left middle turbinate, in contact with the nasal septum.

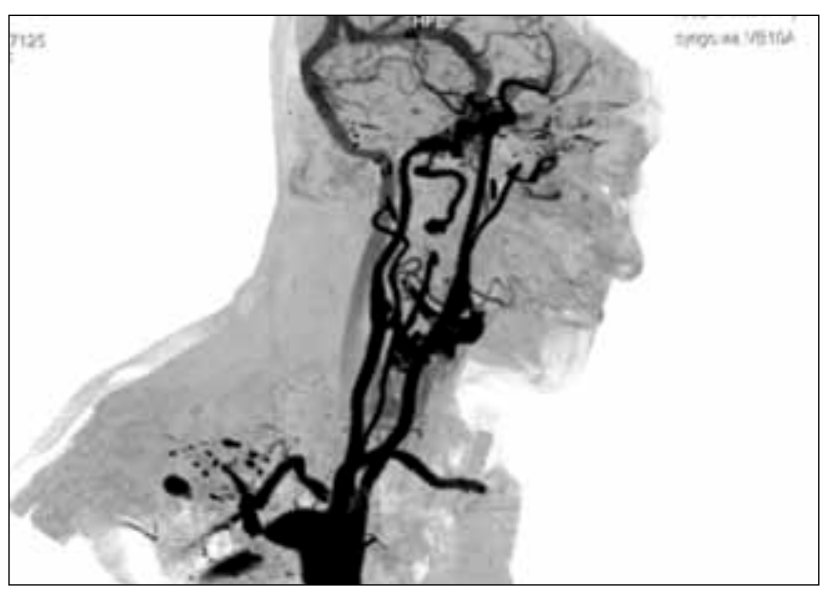

Figure 7 Angiography

ence or there are also unconcerned doctors who are superficial in patient approach.

Regarding postoperative epistaxis after excision of vascular tumors, it can be avoided if we have an optimal preoperative preparation (a good radiological assessment with angiography and selective embolization), a rigorous and accurate tumour dissection with careful haemostasis during surgery. Also, the anaesthesiologists have an important role, because they must control the blood pressure in terms of keeping low values during the surgery and to keep it from bouncing after the surgical act. From our point of view and based on the recent literature regarding epistaxis management, we consider that a complete and rigorous assessment based on clinical, paraclinical investigations (especially nasal endoscopic examination) and thorough patient history are the most important steps in order to establish the bleeding site and severity, the underlying cause and the appropriate treatment alternative. Concerning the treatment, we find the electrocauterization the best option for nasal bleeding ceasing (when there are no contraindications or technical impediments) due to its high success rate and low complications rate.

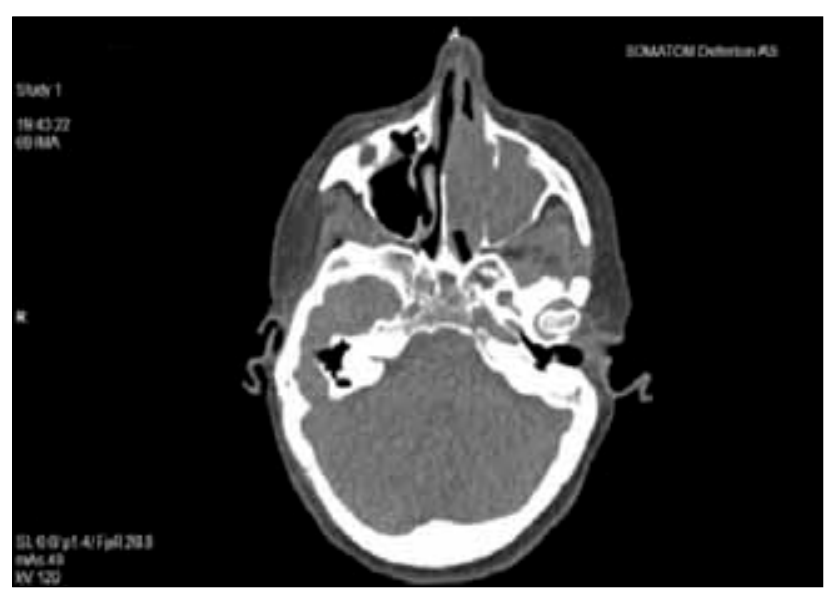

Figure 6 Cranio-facial CT aspect (axial slice).

In our opinion, antero-posterior nasal packing should be performed only in case of impossibility of electrocauterization (e.g. inexperienced doctor, lack of technical equipment), because of the important patient discomfort, high failure rate cited in the literature and because of the large amount of complications that nasal packing can lead to.

Instead of conclusions, we will point out a few myths and facts about nasal bleeding that are commonly encountered among patients and doctors:

- When nose bleeding, lay back and rise the opposite hand - FALSE - the blood will be swallowed, causing nausea and vomiting because of its irritating effect on the gastric mucosa.

- Medium or severe epistaxis in emergency - only nasal packing as first intention - FALSE - when the needed devices and an experienced doctor in endoscopic surgery are available, then electric cauterization is preferred to nasal packing.

- The longer the nasal packing kept, the better the haemostasis. - FALSE - the longer the nasal packing kept, the more complications encountered.

- All patients with nasal bleeding must receive systemic vitamin $\mathrm{K}$ - FALSE - only patients with hepatic diseases that cannot synthesize it in the liver.

- After electrocauterization admission is mandatory. - PARTIALY FALSE - admission is required in case of patients with associated pathology who require a careful follow-up.

- Preoperative embolization prevents $100 \%$ bleeding during surgery - FALSE - embolization is not infallible because of the anatomical variants and the movement possibility of the embolization agents ${ }^{47}$.

Conflict of interest: The authors have no conflict of interest.

Contribution of authors: All authors have equally contributed to this work. 


\section{REFERENCES}

1. Daudia A, Jaiswal V, Jones NS. Guidelines for the management of idiopathic epistaxis in adults: how we do it. Clinical Otolaryngol. 2008;33(6):618-20. DOI:10.1111/j.1749-4486.2008.01795.x.

2. Paul J, Kanotra SP, Kanotra S. Endoscopic Management of Posterior Epistaxis. Indian J Otolaryngol Head Neck Surg. 2011;63(2):141-4. DOI 10.1007/s12070-010-0054-0.

3. Pond F, Sizeland A. Epistaxis strategies for management. Australian Family Physician. 2000;29(10):933-8.

4. Beran M, Petruson B. Occurrence of epistaxis in habitual nose-bleeders and analysis of some etiological factors. ORL J Otorhinolaryngol Relat Spec. 1986;48(5):297-303.

5. Manfredini R, Portaluppi F, Salmi R, Martini A, Gallerani M. Circadian variation in onset of epistaxis: analysis of hospital admissions. BMJ. 2000;321:1112. DOI: https://doi.org/10.1136/bmj.321.7269.1112.

6. Kaluskar SK. Endoscopic sinus surgery: a practical approach. London: Springer-Verlag; 1977, p.107-110.

7. Résultats de l'Observatoire français de l'épistaxis. Revue Officielle de la Société Française d'O.R.L. 2002;75:62-67.

8. Tabassom A, Cho JJ. Epistaxis (Nose Bleed). [Update 2017 May 25] In: StatPearls [Internet]. Treasure Island (FL): Stat Pearls Publishing; 2017. Available from: https://www.ncbi.nlm.nih.gov/books/NBK435997/

9. Klotz DA, Winkle MR, Richmon J, Hengerer AS. Surgical management of posterior epistaxis: a changing paradigm. Laryngoscope. 2002;112(9):1577-82.

10. Viehweg TL, Roberson JB, Hudson JW. Epistaxis: diagnosis and treatment. J Oral Maxillofac Surg. 2006;64(3):511-8. DOI:S0278-2391(05)01815-X.

11. Loukil H, Snoussi M, Fourati H, Frikha F, Salah RB, Jallouli M, et al. Liver involvement in Rendu-Osler disease: a case report and review of literature. Pan Afr Med J. 2016;24:326. DOI: 10.11604/pamj.2016.24.326.9816.

12. Boujrad S, El Hasbaoui B, Echahdi H, Malih M, Agadr A. Factor V congenital deficiency: about a case. Pan Afr Med J. 2017;27:182. DOI: 10.11604/pamj.2017.27.182.12285.

13. Mohamed OM, Govindan A, Filimonov A, Sylvester MJ, Zaki M, Baredes S, et al. Impact of liver disease on outcomes of patients hospitalized for epistaxis. Laryngoscope. 2017. DOI: 10.1002/lary.26624. [Epub ahead of print]

14. Bertrand B, Eloy Ph, Rombaux Ph, Lamarque C, Watelet JB, Collet S. Guidelines to the management of epistaxis. B-ENT. 2005;1 (Suppl. 1):27-43.

15. Guarisco JL, Graham HD 3rd. Epistaxis in children: causes, diagnosis, and treatment. Ear Nose Throat J. 1989;68(7):522, 528-30, 532 passim.

16. Bailey BJ. Johnson JT, Newlands SD, Calhoun KH, Deskin RW, eds. Head and Neck Surgery-Otolaryngology. 4th ed. Philadelphia, PA: Lippincott Williams \& Wilkins; 2006.

17. Lloyd S, Almeyda J, Di Cuffa R, Shah K. The effect of silver nitrate on nasal septal cartilage. Ear Nose Throat J. 2005;84(1):41-4.

18. Cho JH, Kim YH. Epistaxis. In: Gendeh BS (ed.). Otolaryngology. InTech; 2012. DOI: 10.5772/37129. Available from: https://www.intechopen. com/books/otolaryngology/epistaxis

19. Newton E, Lasso A, Petrcich W, Kilty SJ. An outcomes analysis of anterior epistaxis management in the emergency department. J Otolaryngol Head Neck Surg. 2016;45:24. DOI:10.1186/s40463-016-0138-2.

20. Johnson N, Faria J, Behar P. A Comparison of Bipolar Electrocautery and Chemical Cautery for Control of Pediatric Recurrent Anterior Epistaxis. Otolaryngol Head Neck Surg. 2015;153(5):851-6. DOI: 10.1177/0194599815589583. Epub 2015 Jun 30.

21. Schreiner L. Complications and errors in the management of nose bleeding (author's transl). Laryngol Rhinol Otol (Stuttg). 1976;55:257-63.

22. Manea C, Sabaru I, Sanda C. Nasal packing in endonasal surgery - a literature review. Romanian Journal of Rhinology. 2011;1(4):210-4.

23. Moumoulidis I, Draper MR, Patel H, Jani P, Price T. A prospective randomised controlled trial comparing Merocel and Rapid Rhino nasal tampons in the treatment of epistaxis. Eur Arch Otorhinolaryngol. 2006;263(8):719-22. Epub 2006 May 10.

24. Derkay CS, Hirsch BE, Johnson JT, Wagner RL. Posterior nasal packing.
Are intravenous antibiotics really necessary? Arch Otolaryngol Head neck Surg. 1989;115(4):439-41.

25. García Callejo FJ, Muñoz Fernández N, Achiques Martínez MT, Frías MoyaAngeler S, Montoro Elena MJ, Algarra JM. Nasal packing in posterior epistaxis. Comparison of two methods. Acta Otorrinolaringologica Esp 2010;61 (3):196-201. DOI: 10.1016/j.otorri.2009.11.005. Epub 2010 Feb 6.

26. Pritikin JB, Caldarelli DD, Panje WR. Endoscopic ligation of the interna maxillary artery for treatment of intractable posterior epistaxis. Ann Otol Rhinol Laryngol. 1998;107(2):85-91.

27. Hashmi S, Gopaul S, Prinsley PR, Sansom JR. Swallowed nasal pack: a rare but serious complication of the management of epistaxis. J Laryngol Otol. 2004;118(5):372-3.

28. Civelek B, Kargi AE, Sensöz O, Erdogan B. Rare complication of nasal packing: alar region necrosis. Otolaryngol Head Neck Surg. 2000;123(5):656-7.

29. Nahass RG, Gocke DJ. Toxic shock syndrome associated with use of a nasal tampon. Am J Med. 1988;84(3 Pt 2):629-31.

30. Pinto JA, Cintra PPV da C, Sônego TB, Leal C de FA, Artico MS, Soares J dos S. Severe complication of posterior nasal packing: Case Report. Int Arch Otorhinolaryngol. 2012;16(4):527-9. DOI: 10.7162/S180997772012000400016.

31. Odat H, Al-Qudah M. Endoscopic monopolar cauterization of the sphenopalatine artery: a single surgeons experience. Ann Saudi Med. 2016;36(6):422-6.

32. O'Donnell M, Robertson G, McGarry GW. A new bipolar diathermy probe for the outpatient management of adult acute epistaxis. Clin Otolaryngol Allied Sci. 1999;24(6):537-41.

33. Zou Y, Deng YQ, Xiao CW, Kong YG, Xu Y, Tao ZZ, et al. Comparison of outcomes between endoscopic surgery and conventional nasal packing for epistaxis in the posterior fornix of the inferior nasal meatus. Pak J Med Scie. 2015;31(6):1361-5. DOI: 10.12669/pjms.316.8340.

34. Wurman LH, Sack JG, Flannery JV Jr., Paulson TO. Selective endoscopic electrocautery for posterior epistaxis. Laryngoscope. 1988;98(12):1348-9 DOI: 10.1288/00005537-198812000-00013.

35. Cummings CW. Cummings Otolaryngology - Head and Neck Surgery. 4th ed. Philadelphia, PA: Elsevier Mosby; 2005

36. Small M, Maran AG. Epistaxis and arterial ligation. J Laryngol Otol 1984;98(3):281-4. DOI: 10.1017/S0022215100146572.

37. Metson R, Lane R. Internal maxillary artery ligation for epistaxis: an analysis of failures. Laryngosocope. 1988;98(7):760-4.

38. Strong EB, Bell DA, Johnson LP, Jacobs JM. Intractable epistaxis: transantral ligation vs. embolization: efficacy review and cost analysis. Otolaryngol Head Neck Surg. 1995;113(6):674-8.

39. Sokoloff J, Wickbom I, McDonald D, Brahme F, Goergen TC, Goldberger LE. Therapeutic percutaneous embolization in intractable epistaxis. Radiology. 1974;111(2):285-7. DOI: 10.1148/111.2.285.

40. Chandler JR, Serrins AJ. Transantral ligation of the internal maxillary artery for epistaxis. Laryngoscope. 1965;75(7):1151-9.

41. Stamm AC, Pinto JA, Neto AF, Menon AD. Microsurgery in severe posterior epistaxis. Rhinology. 1985;23(4):321-5.

42. Elden L, Montanera W, Terbrugge K, Willinsky R, Lasjaunias P, Charles D. Angiographic embolization for the treatment of epistaxis: a review of 108 cases. Otolaryngol Head Neck Surg. 1994;111(1):44-50.

43. Strach K, Schröck A, Wilhelm K, Greschus S, Tschampa H, Mohlenbruch $\mathrm{M}$, et al. Endovascular treatment of epistaxis: indications, management, and outcome. Cardiovasc Intervent Radiol. 2011;34(6):1190-8. DOI: 10.1007/s00270-011-0155-5. Epub 2011 Apr 7.

44. Loaëc M, Moriniere S, Hitier M, Ferrant O, Plauchu H, Babin E. Psychosocial quality of life in hereditary haemorrhagic telangiectasia patients. Rhinology. 2011;49(2):164-7. DOI: 10.4193/Rhino10.090.

45. Sadick H, Naim R, Oulmi J, Hormann K, Bergler W. Plasma surgery and topical estriol: effects on the nasal mucosa and long-term results in patients with Osler's disease. Otolaryngol Head Neck Surg. 2003;129(3):233-8.

46. Rimmer J, Lund VJ. Hereditary haemorrhagic telangiectasia. Rhinology. 2015;53(3):195-203.

47. Wang B, Zu QQ, Liu XL, Zhou CG, Xia JG, Zhao LB, et al. Transarterial embolization in the management of intractable epistaxis: the angiographic findings and results based on etiologies. Acta Otolaryngol. 2016;136(8):864 8. DOI: 10.3109/00016489.2016.1164896. Epub 2016 Apr 8. 